\title{
Targeting the microRNA-34a as a Novel Therapeutic Strategy for Cardiovascular Diseases
}

\section{OPEN ACCESS}

Edited by:

Paul H. A. Quax,

Leiden University, Netherlands

Reviewed by:

Roel Bijkerk,

Leiden University Medical Center, Netherlands

Julie R. McMullen,

Baker Heart and Diabetes Institute, Australia

Zhi Xin Shan,

Guangdong Provincial People's

Hospital, China

*Correspondence:

Jiu-Chang Zhong

jczhong@sina.com

Le-Feng Wang

drwlf311@sina.com

tORCID:

Jiu-Chang Zhong

orcid.org/0000-0002-2315-3515

Le-Feng Wang

orcid.org/0000-0003-1271-0993

FThese authors have contributed equally to this work

Specialty section:

This article was submitted to General Cardiovascular Medicine,

a section of the journal

Frontiers in Cardiovascular Medicine

Received: 27 September 2021 Accepted: 28 December 2021 Published: 27 January 2022

Citation:

Hua C-C, Liu X-M, Liang L-R Wang L-F and Zhong J-C (2022) Targeting the microRNA-34a as a

Novel Therapeutic Strategy for

Cardiovascular Diseases.

Front. Cardiovasc. Med. 8:784044.

doi: 10.3389/fcvm.2021.784044

\author{
Cun-Cun Hua ${ }^{1 \neq}$, Xin-Ming Liu ${ }^{1 \neq}$, Li-Rong Liang ${ }^{2}$, Le-Feng Wang ${ }^{1 * t}$ and \\ Jiu-Chang Zhong ${ }^{1,2,3 * t}$
}

\begin{abstract}
${ }^{1}$ Heart Center and Beijing Key Laboratory of Hypertension, Beijing Chaoyang Hospital, Capital Medical University, Beijing, China, ${ }^{2}$ Department of Clinical Epidemiology and Tobacco Dependence Treatment Research, Beijing Institute of Respiratory Medicine, Beijing, China, ${ }^{3}$ Beijing Institute of Respiratory Medicine, Capital Medical University, Beijing, China
\end{abstract}

Cardiovascular diseases (CVDs) are still the main cause of morbidity and mortality worldwide and include a group of disorders varying from vasculature, myocardium, arrhythmias and cardiac development. MicroRNAs (miRs) are endogenous non-coding RNAs with 18-23 nucleotides that regulate gene expression. The miR-34 family, including $\mathrm{miR}-34 \mathrm{a} / \mathrm{b} / \mathrm{c}$, plays a vital role in the regulation of myocardial physiology and pathophysiological processes. Recently, miR-34a has been implicated in cardiovascular fibrosis, dysfunction and related cardiovascular disorders as an essential regulator. Interestingly, there is a pivotal link among miR-34a, cardiovascular fibrosis, and Smad4/TGF- $\beta 1$ signaling. Notably, both loss-of-function and gain-of-function approaches identified the critical roles of miR-34a in cardiovascular apoptosis, autophagy, inflammation, senescence and remodeling by modulating multifunctional signaling pathways. In this article, we focus on the current understanding of miR-34a in biogenesis, its biological effects and its implications for cardiac pathologies including myocardial infarction, heart failure, ischaemia reperfusion injury, cardiomyopathy, atherosclerosis, hypertension and atrial fibrillation. Thus, further understanding of the effects of miR-34a on cardiovascular diseases will aid the development of effective interventions. Targeting for miR-34a has emerged as a potential therapeutic target for cardiovascular dysfunction and related diseases.

Keywords: microRNA-34a, cardiovascular fibrosis, apoptosis, myocardial remodeling, heart dysfunction

\section{INTRODUCTION}

Cardiovascular diseases (CVDs) are regarded as the leading cause of human death worldwide (1). Extensive studies have focused on the pathogenesis of CVDs, but the underlying pathophysiological mechanism is still not clear. Therefore, investigations into the molecular basis of CVDs may elucidate a new pathway for treatment in clinical practice. MicroRNAs (miRs) are endogenous non-coding RNAs with 18-23 nucleotides that regulate gene expression by binding complementary sequences in the $3^{\prime} \mathrm{UTR}$ of mRNAs. MiRs are indispensable in various biological processes and are involved in cell differentiation and proliferation, cell death, and metabolism (2). In the cardiovascular system, miRs regulate cellular pathways in cardiac fibrosis, apoptosis, inflammation, autophagy and senescence. Recent studies have identified that miRs are involved in multiple CVDs. The role of miR-34 family in regulating cardiac function is notable. 
The miR-34 precursor family was discovered computationally and identified experimentally later. Three mature miRs, miR-34a, miR-34b, and miR-34c, are processed by two different precursors. The miR-34 family is transcribed from two distinct sets of genes located on chromosomes 1 and 11 (3). MiR-34a expression is higher than miR34b/c expression in most human organs and tissues except in the lungs (4). Currently, miR-34a expression is mainly regulated by epigenetic modification, transcriptional regulation and other molecular mechanisms (5). Notably, miR$34 \mathrm{a}$ has been elucidated to play crucial roles in diverse cardiac biological pathways including apoptosis, inflammation, autophagy, aging and fibrosis, which ultimately contribute to cardiac dysfunction, suggesting the therapeutic potential of targeting miR-34a in CVDs. This review article will discuss the biological effects of miR-34a and summarize the current understanding of miR-34a in the development and prevention of CVDs, including myocardial infarction (MI), heart failure (HF), ischaemia reperfusion (I/R) injury, cardiomyopathy, atherosclerosis, hypertension and atrial fibrillation (AF).

\section{BIOGENESIS AND BIOLOGICAL EFFECTS OF MIR-34A}

MiRs are small non-coding RNAs which regulate gene expression by binding to complementary sequences in the 3'UTR of mRNAs. The miR-34 family was found to be increased in heart tissue from patients with cardiovascular diseases and encoded by two different genes (6). MiR-34a is encoded by its own transcript, while miR-34b and miR-34c are encoded by the same primary transcript (7). Similar to the biogenesis of all miRs, miR-34a is transcribed from the transcription start site in the nucleus by RNA polymerase II/III as a long hairpin molecule (pri-miR) and then cleaved by an RNase III Drosha to a $\sim 70$-nucleotide long stem-loop precursor (pre-miR). The pre-miR is transported from the nucleus to the cytoplasm and is further cleaved by an RNase III Dicer into 22-nucleotide long mature strands, which are consolidated into the RNA-induced silencing complex (Figure 1). This complex downregulates target transcripts by mRNA degradation or inhibition of translation $(8,9)$. The human miR-34a precursor is transcribed from chromosome 1 and maps to the distal region of chromosome $1 \mathrm{p}$. It is encoded in the second exon of a gene located on chromosome 1p36.22 (10, 11). MiR-34a is involved in cellular diseases and is recognized as an essential regulator in cardiovascular diseases (12).

It has been reported that overexpression of miR-34a promotes apoptosis of MI by inhibiting the activity of silent information regulator 1 (SIRT1) (13). Phosphatase and tensin homolog (PTEN), a negative regulator of PI3K signaling, was downregulated, while miR-34a expression was increased and mRNA of SIRT1 was decreased in oxidative stress-induced epithelial cells (Figure 2) (14). In addition, Notch1, Smad4, and fork head box O3 (FOXO3) were verified as miR-34a target genes (Figure 1) (11, 15), all of which have actions relevant to cardiovascular diseases. In congenital heart disease (CHD), overexpression of miR-34a induced the deduction of embryonic endocardial cells (ECCs) and acceleration of cell apoptosis, further increasing the risk of CHD targeting Notch1 through the Notch signaling pathway (Figure 2) (16). Interestingly, hypoxia-induced HIF1 $\alpha$ accelerated angiogenesis of trophoblast cells through the Notch1/ endothelial receptor type B (ETBR) signaling pathway (17). ETBR antagonist increases apoptosis and susceptibility to an apoptotic agent in human pulmonary arterial smooth muscle cells, further promoting vascular remodeling in pulmonary artery hypertension (Figure 2) (18). Additionally, miR-34a enhanced cardiac fibrosis after MI via targeting Smad4 related with TGF- $\beta 1$ signaling pathway while miR-34a inhibition ameliorated the above changes (Table 1; Figure 2) (19). PNUTS, also known as PPP1R10, was identified as a target gene of miR-34a, a novel, SIRT1 independent of the miR-34a signaling pathway, plays a vital role in many cellular processes including cell cycle progression, DNA damage responses (DDR), and apoptosis. It has been reported that PNUTS plays a major role in the anti-senescence effect of doxorubicin (DOXO)-induced H9C2 cell aging. More importantly, inhibition of miR-34a improves cardiac function during aging and post MI by reducing cell death and fibrosis by targeting PNUTS, which is an essential regulator of endogenous cardiac regeneration (Table 1; Figure 1) $(20,29)$. MiR-34a accelerated the progression of atherosclerosis by regulating FOXO3 expression. It was reported that FOXO3 plays a critical role in restraining oxidative damage in ox-LDLinduced endothelial cell injury via the miR-34a/SIRT1/FOXO3 signaling pathway (Table 1; Figure 2) (21). FOXO3 inhibited the transcription of pro-apoptotic gene p53 upregulated modulator of apoptosis (PUMA) to promote cell apoptosis (Figure 2) (30). It was identified that inhibition of miR-34a-5p alleviated lipopolysaccharide-induced human umbilical vein endothelial cells (HUVECs) injury by targeting FOXM1 through activating the Nuclear factor-E2-related factor 2 (NRF2)/HO-1 pathway (Figure 2) (31).

Collectively, miR-34a plays a vital role in controlling cellular apoptosis, autophagy, inflammation, aging, fibrosis, and remodeling through Smad4/TGF- $\beta 1$, FOXO3/PUMA, Notch1/ETBR, PTEN/PI3K/SIRT1 and FOXM1/NRF2/HO-1 signaling pathways.

\section{MIR-34A AND APOPTOSIS IN THE CARDIOVASCULAR SYSTEM}

Apoptosis as one of the cell death programs contributes significantly to multiple cardiovascular diseases such as MI, myocardial ischaemia/reperfusion injury (MIRI), and HF with reduced ejection fraction (32). MiR-34a is expressed abundantly in multiple cardiovascular disease induced apoptosis. A large number of studies have revealed that miR-34a regulates cellular apoptosis through p53-dependent or independent pathway. In p53-dependent pathway, miR-34a-induced apoptosis partly relies on the wild-type p53 genes at least, and p53 is induced by miR$34 \mathrm{a}$, suggesting that miR-34a can also function in a feedback loop to p53 (11). The tumor suppressor p53 is critical for tumor prevention through regulating cell-cycle checkpoints, while loss of p53 function tends to result in human cancer (33). More importantly, ablation of p53 contributed to cardiomyocyte 


\section{A}

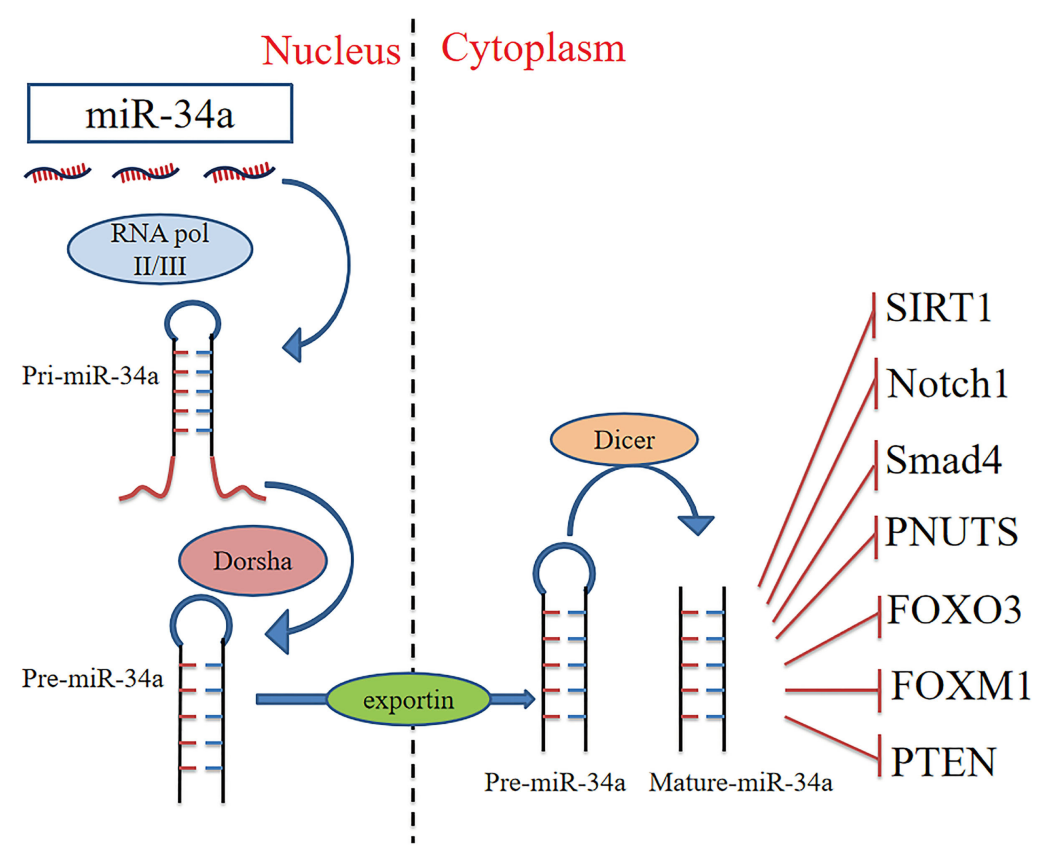

B

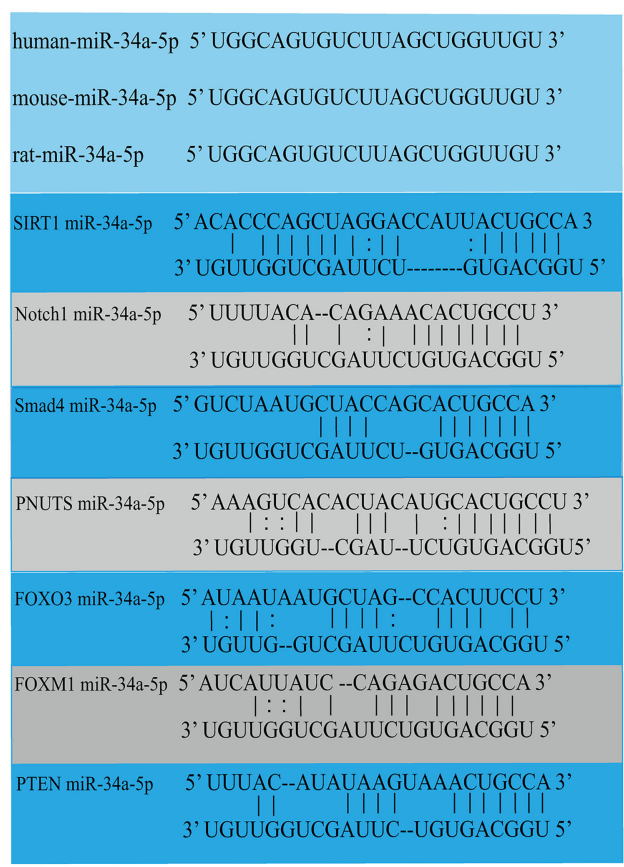

FIGURE 1 | Schematic diagram of the activities of miR-34a, and potential binding sites between miR-34a and the target genes. (A) Schematic diagram of the activities, and target genes of miR-34a. (B) The sequence of miR-34a-5p is conserved in humans, mice and rats. The potential miR-34a-5p-binding sites of target genes. FOXM1, Forkhead box M1; FOXO3, Fork head box O3; PTEN, Phosphatase and tensin homologue; SIRT1, Silent information regulator 1.

apoptosis and spontaneous hypertrophy in HF by regulating the cardiac transcriptome. This suggests that $\mathrm{p} 53$ plays a pleiotropic role in cardiac tissue homeostasis and function (34). As a target of p53, miR-34a targets Bcl2 and SIRT1 to aggravate myocardial injury by exacerbating apoptosis and infarct size, decreasing left ventricular function (35). Intriguingly, SIRT1, one of the main targets of miR-34a, mediates cellular responses involving apoptosis, autophagy and mitochondrial biogenesis, which suppress the activity of p53 by posttranscriptional deacetylation of the p53 protein (Figure 1) $(9,36,37)$. Additionally, research have found that p53 and miR-34a interact in a positive feedback loop and target SIRT1 involved in cell cycle progression, cellular senescence and apoptosis. The above results indicated that miR34 a may regulate cardiac homeostasis and cellular apoptosis by modulating p53 function. Interestingly, the research has founded that the ratio of miR-34a to SIRT1 was increased in older patients' myocardial tissue rather than in young patients post MI, implying severe apoptosis in older patients and explained why older patients recovered more slowly than young patients.

It has been accepted that miR-34a modulates cellular apoptosis in cardiovascular system in a manner dependent on cell types. Recent study reported that miR-34a promotes apoptosis and angiogenesis of cardiac microvascular endothelial cells (CMECs), and upregulates inflammatory cytokines, thus worsening CMECs damage through the Notch signaling pathway (Table 1) (22). In hypoxia-induced cardiomyocytes, the expression of miR-34a-5p was increased while miR34a-5p knockdown ameliorated cardiomyocyte apoptosis and cardiac dysfunction by upregulating ZEB1 and antiapoptotic proteins such as aldehyde dehydrogenase 2 (38). In a diabetic cardiomyopathy rat model, granulocyte-colony stimulating factor ameliorated diastolic dysfunction and reduced cardiomyocyte apoptosis through downregulation of miR-34a and upregulation of $\mathrm{Bcl} 2$ (39). However, the effect of inhibition of miR-34a was not observed in cardiac progenitor cells, which showed reduced proliferation (39). Suppression of miR-34a activity may have diverse effects depending on cell types, thus it is necessary to eliminate off-target effects by introducing miR-based therapy.

The Notch signaling pathway is involved in processes related to cell differentiation, proliferation, apoptosis and survival. In a rat model of CHD, miR-34a targeted Notch1, improved the expression of Jagged1, Hes1, and Hey2, promoted the apoptosis rate and decreased the proliferation rate (Figure 1) (16). Similar to MIRI-induced microvascular injury, inhibition of miR-34a alleviates brain tissue damage and neuronal apoptosis by activating the Notch $1 / \mathrm{HIF}-1 \alpha$ signaling pathway in a cerebral I/R-induced rat model (40). Additionally, adenosine deaminases acting on RNA 2 (ADAR2), an enzyme acting on doublestranded RNAs, promoted cardiomyocyte proliferation and inhibited DOXO-induced cell apoptosis via the ADAR2/miR34 a regulation axis, which involves the RNA editing activity of ADAR2 (41). These findings indicated that miR-34a promoted 


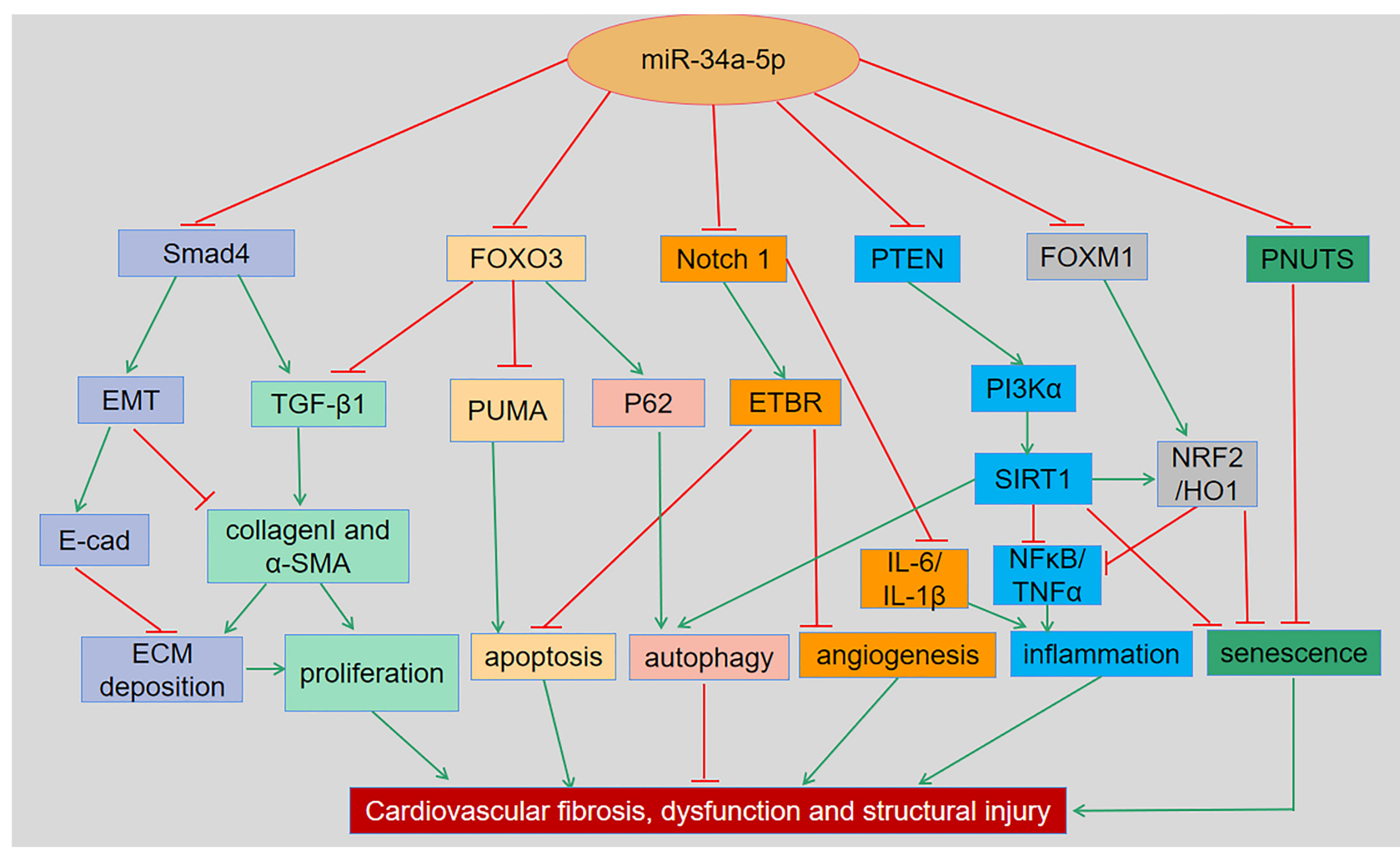

FIGURE 2 | The regulatory roles and underlying mechanisms of miR-34a in cardiovascular dysfunction and related disorders. MiR-34a has been shown to regulate cellular apoptosis, autophagy, inflammation, senescence and remodeling in various cardiac and vascular tissues and cells through Smad4/TGF- $\beta 1$, FOXO3/PUMA, Notch1/ETBR, PTEN/PI3K/SIRT1, and FOXM1/NRF2/HO-1 signaling pathways, respectively. EMT, Epithelial-mesenchymal transition; ECM, Extracellular matrix; ETBR, endothelial receptor type B; FOXM1, Forkhead box M1; FOXO3, Forkhead box O3; NRF2, Nuclear factor-E2-related factor 2; PI3K, Phosphatidylinositol 3-kinase; PNUTS, Phosphatase-1 nuclear targeting subunit; PTEN, Phosphatase and tensin homologue; PUMA, p53-up-regulated modulator of apoptosis; SIRT1, Silent information regulator 1 ; TGF- $\beta 1$, Transforming growth factor $\beta 1$.

cardiomyocyte apoptosis and aggravated myocardial injury through different mechanisms.

\section{MIR-34A AND AUTOPHAGY IN THE CARDIOVASCULAR SYSTEM}

Autophagy plays a vital role in the development of various cardiovascular diseases (42). It has been reported that miR34a suppresses autophagy in cancer cells (43). However, autophagy regulated by miR-34a has also been demonstrated in cardiovascular disease. The inhibition of miR-34a enhanced cardiomyocyte autophagy and further ameliorated cardiac function in diabetic cardiomyopathy (44). In addition, miR$34 \mathrm{a}$ has been shown to inhibit autophagy after cardiac I/R injury by regulating TNF- $\alpha$ expression, thereby ameliorating myocardial damage (45). Interestingly, miR-34a-5p was found to be elevated in human coronary artery endothelial cells (HCAECs) exposed to chronic intermittent hypoxia (CIH), further increasing autophagy-related proteins such as Beclin and LC3. These results indicated that miR-34a-5p contributed to $\mathrm{CIH}$-induced HCAECs autophagy through Bcl2/Beclin signaling pathways. MiR-34a-5p has been recognized as a potential therapeutic target for autophagy induced by $\mathrm{CIH}$ which leads to CVDs (46). Accordingly, miR-34a inhibition improves cardiac function by regulating protective autophagy in CVDs.

\section{MIR-34A AND CARDIOVASCULAR OXIDATIVE STRESS AND INFLAMMATION}

MiR-34a is a driver of vascular and systemic inflammation, which promotes the progression of inflammation related disease (47). Overexpression of miR-34a enhanced radiationinduced oxidative stress in cardiomyocyte, while macrophage migration inhibition reduced cellular reactive oxygen species (ROS) through the miR-34a/SIRT1 signaling pathway (48). More importantly, inhibition of miR-34a mitigated oxidative stress induced by $\mathrm{H}_{2} \mathrm{O}_{2}$ to protect vascular endothelial cells by targeting SIRT1 (49). The role of inflammation in MIRI is still controversial. Enhancement of circulating monocyte levels and attenuated repair capacity after MI have been found in apolipoprotein E-null mice (50). In an additional study, antiinflammatory therapy was shown to reduce the number of cardiac adverse events post MI (51). MI and MIRI have been shown to cause a burst of ROS accumulation. Down-regulation 
TABLE 1 | The regulatory roles and underlying mechanisms of miR-34a in cardiovascular dysfunction and disorders.

\begin{tabular}{|c|c|c|c|}
\hline $\begin{array}{l}\text { Experimental } \\
\text { model }\end{array}$ & $\begin{array}{l}\text { Experimental } \\
\text { intervention }\end{array}$ & Effects & References \\
\hline Ml mouse model & $\begin{array}{l}\text { miR-34 family } \\
\text { inhibitor }\end{array}$ & $\begin{array}{l}\uparrow \text { Vinculin, SIRT1, PNUTS, } \\
\text { Notch1 } \\
\uparrow B c 16 \text {, Sema4b } \\
\downarrow \text { Left ventricular remodeling } \\
\uparrow \text { Cardiac function }\end{array}$ & (6) \\
\hline $\begin{array}{l}\text { DOXO-induced } \\
\text { myocardium }\end{array}$ & $\begin{array}{l}\text { miR-34a } \\
\text { inhibitor }\end{array}$ & $\begin{array}{l}\uparrow \text { Bcl2, SIRT1 } \\
\downarrow \text { Apoptosis and } \\
\text { senescence } \\
\downarrow \text { Myocardial fibrosis and } \\
\text { inflammation } \\
\downarrow \text { Cardiac dysfunction }\end{array}$ & (12) \\
\hline $\begin{array}{l}\text { Ml-induced rat } \\
\text { myocardium }\end{array}$ & $\begin{array}{l}\text { miR-34a } \\
\text { mimic }\end{array}$ & $\begin{array}{l}\downarrow \mathrm{Bcl} 2, \mathrm{SIRT} 1 \\
\uparrow \mathrm{Bax} \\
\uparrow \text { Apoptosis }\end{array}$ & (13) \\
\hline Ml rat model & $\begin{array}{l}\text { miR-34a } \\
\text { inhibitor }\end{array}$ & $\begin{array}{l}\downarrow \text { Apoptosis } \\
\downarrow \text { TGF- } \beta 1 \\
\downarrow \text { Collagenl, } \alpha \text {-SMA, ECM } \\
\text { deposition }\end{array}$ & (19) \\
\hline $\begin{array}{l}\text { Cardiac } \\
\text { fibroblast post } \\
\text { MI }\end{array}$ & pre-miR-34a & $\begin{array}{l}\uparrow \text { Collagen I, } \alpha \text {-SMA, } \\
\text { fibronectin } \\
\uparrow T G F-\beta 1, \text { Smad4 } \\
\uparrow \text { Proliferation, migration }\end{array}$ & (19) \\
\hline Aged mouse & $\begin{array}{l}\text { miR-34a } \\
\text { inhibitor }\end{array}$ & $\begin{array}{l}\uparrow P N U T S \\
\downarrow \text { Apoptosis, cell death } \\
\downarrow \text { Cardiac hypertrophy } \\
\uparrow \text { Cardiac contractile } \\
\text { function }\end{array}$ & (20) \\
\hline $\begin{array}{l}\text { Mouse model of } \\
\text { AMI }\end{array}$ & $\begin{array}{l}\text { miR-34a } \\
\text { inhibitor }\end{array}$ & $\begin{array}{l}\uparrow \text { PNUTS } \\
\downarrow \text { Apoptosis } \\
\downarrow \text { Fibrosis } \\
\uparrow \text { Capillary density } \\
\uparrow \text { Cardiac contractile } \\
\text { function }\end{array}$ & (20) \\
\hline $\begin{array}{l}\text { ox-LDL-elicited } \\
\text { HUVECs }\end{array}$ & $\begin{array}{l}\text { miR-34a } \\
\text { mimic }\end{array}$ & $\begin{array}{l}\uparrow R O S, \text { MDA } \\
\downarrow S O D, C A T, G S H, G P x, \\
\text { SIRT1, FOXO3a } \\
\uparrow O x i d a t i v e ~ s t r e s s\end{array}$ & $(21)$ \\
\hline Mouse CMECs & $\begin{array}{l}\text { miR-34a } \\
\text { mimic }\end{array}$ & $\begin{array}{l}\uparrow I L-1 \beta, \text { IL-6 } \\
\downarrow \text { Notch1, IL-10, VEGF, } \\
\text { bFGF, HGF } \\
\uparrow A p o p t o s i s \\
\downarrow \text { Cell viability and } \\
\text { capillary-like } \\
\text { structures of cells formation } \\
\text { ability }\end{array}$ & $(22)$ \\
\hline $\begin{array}{l}\text { ISO-induced rat } \\
\text { myocardial } \\
\text { fibrosis model }\end{array}$ & $\begin{array}{l}\text { miR-34a } \\
\text { inhibitor }\end{array}$ & $\begin{array}{l}\uparrow c \text {-Ski } \\
\downarrow \text { Collagen I, } \alpha \text {-SMA, TGF- } \beta 1 \\
\downarrow \text { Cardiac fibrosis } \\
\downarrow \text { Cell proliferation }\end{array}$ & (23) \\
\hline $\begin{array}{l}\text { RBFox } 2 \mathrm{KO} \\
\text { mice }\end{array}$ & $\begin{array}{l}\text { miR-34a } \\
\text { inhibitor }\end{array}$ & $\begin{array}{l}\uparrow \mathrm{JPH} 2 \\
\downarrow \text { Anf } \\
\uparrow \text { Cardiac function }\end{array}$ & (24) \\
\hline $\begin{array}{l}\text { H/R induced } \\
\text { mouse } \\
\text { cardiomyocytes }\end{array}$ & $\begin{array}{l}\text { miR-34a } \\
\text { inhibitor }\end{array}$ & $\begin{array}{l}\downarrow \text { Bax, caspase } 3 \\
\uparrow \text { Bcl } 2 \\
\downarrow \text { ER stress and cell } \\
\text { apoptosis }\end{array}$ & $(25)$ \\
\hline $\begin{array}{l}\text { Apoe-/- mice } \\
\text { fed with HFD }\end{array}$ & $\begin{array}{l}\text { miR-34a } \\
\text { inhibitor }\end{array}$ & $\begin{array}{l}\uparrow \mathrm{Bc} 2 \\
\downarrow \text { Bax, Caspase-3, and } \\
\text { caspase-9 }\end{array}$ & (26) \\
\hline
\end{tabular}

(Continued)
TABLE 1 | Continued

\begin{tabular}{|c|c|c|c|}
\hline $\begin{array}{l}\text { Experimental } \\
\text { model }\end{array}$ & $\begin{array}{l}\text { Experimental } \\
\text { intervention }\end{array}$ & Effects & References \\
\hline & & $\begin{array}{l}\uparrow \text { Cell growth and viability } \\
\downarrow \text { Atherosclerotic lesions }\end{array}$ & \\
\hline $\begin{array}{l}\text { IS-induced } \\
\text { HUVECs and HA } \\
\text { VSMCs }\end{array}$ & & $\begin{array}{l}\uparrow m i R-34 a, \text { p53 } \\
\downarrow \text { Notch-1, SIRT1, Wnt-1, } \\
\text { Jag1, } \\
\downarrow \text { Proliferation, migration } \\
\uparrow \text { Apoptosis }\end{array}$ & (27) \\
\hline $\begin{array}{l}\text { Wire injury CAVS } \\
\text { mice }\end{array}$ & $\begin{array}{l}\text { miR-34a } \\
\text { inhibitor }\end{array}$ & $\begin{array}{l}\uparrow \text { Notch1 } \\
\downarrow \text { Runx2, a-SMA, VCAM1, } \\
\text { Cadherin } \\
\downarrow \text { LVEDD } \\
\downarrow \text { Intraventricular septum } \\
\text { diameter } \\
\downarrow \text { Aortic velocity, aortic valve } \\
\text { tissue area } \\
\downarrow \text { Calcium deposition }\end{array}$ & (28) \\
\hline
\end{tabular}

ALDH2, Aldehyde dehydrogenase 2; Anf, atrial natriuretic factor; ApoE-/-, Apolipoprotein E-defcient; $\alpha$-SMA, $\alpha$-smooth muscle actin; bFGF, Basic fibroblast growth factor; Bcl-2, B-cell lymphoma-2; Bax, Bcl-2 associated X protein; CAVS, Calcific aortic valve stenosis; CAT, catalase; CMECs, Cardiac microvascular endothelial cells; DOXO, doxorubicin; EF, ejection fraction; ER, Endoplasmic reticulum; FS, fractional shorting; GSH, glutathione, GPX, glutathione peroxidase; HCY, Homocystein; HGF, Human growth factor; HFD, high-fat diet; HUVECs, human umbilical vein endothelial cells; HAVSMCs, human aortic

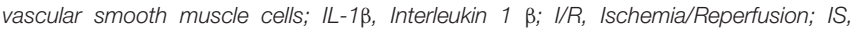
indoxyl sulfate; ISO, isoproterenol; LVEDD, left ventricular end-diastolic diameter; MI, Myocardial infarction; MDA, malondialdehyde; NF-kB, Nuclear factor kappa-B; ROS, reactive oxygen species; Runx2, Runt-related transcription factor 2; SIRT1, Silen information regulator 1; Sema4b, semaphorin 4B; SOD, superoxide dismutase; TGF- $\beta$, Transforming growth factor $\beta$; VCAM1, vascular cell adhesion molecule 1; VEGF, Vascular endothelial growth factor.

of miR-34a alleviates the inflammatory response induced by renal I/R by promoting Kruppel-like factor 4 (KLF4) levels in rats (52). Similarly, miR-34a is involved in cancer immunotherapymediated myocardial inflammation. Cancer immune therapy has become a well-known treatment for some cancers, but immune checkpoint inhibitors (ICIs) more often lead to cardiac injury. It has been reported that inhibition of miR-34a attenuates cardiomyocyte inflammation induced by ICIs targeting KLF4 which has a cardioprotective effect. This result indicated that targeting the miR-34a/KLF4 signaling pathway may be an effective approach for patients who experience ICISs therapyinduced cardiac injury (53). In general, treatment with the miR34a inhibitor may alleviate cardiomyocyte inflammation and oxidative stress. However, further studies are needed to identify the role of miR-34 in the treatment of inflammation-mediated MI and MIRI.

\section{MIR-34A AND CARDIOVASCULAR SENESCENCE}

Age-related cardiac disease is driven by multiple molecular mechanisms such as telomere shortening, DDR, accumulation of somatic mutations, epigenetic changes, and alterations in non-coding RNAs regulating gene expression (54). Radiotherapy increases the survival of various cancer patients but leads to 
cardiac dysfunction, including cardiomyocyte senescence. A recent study demonstrated that the expression of miR-34a was obviously increased in the radiation-induced cardiac dysfunction to exert a pro-senescence effect on cardiomyocytes by regulating SIRT1 (Figure 2). Additionally, overexpression of miR-34a leads to a reduction in both the mRNA and protein levels of SIRT1/6, which are putative anti-aging enzymes, thereby promoting aging responses under oxidative stress (14). In the DOXO treated rat model, silencing of miR-34a ameliorated DOXO-induced myocardial senescence and protected cardiac function and integrity by targeting Bcl2 and SIRT1 (Table 1) (12). Suppression of miR-34a does not solely inhibit cardiomyocyte senescence but likewise plays a regulatory role in vascular senescence. A recent review generalized the role of miR-34a in vascular aging and senescence, demonstrating that miR-34a promoted vascular aging through targeting SIRT1 or regulating vascular cell adhesion protein 1 and intercellular adhesion molecule 1 at least partially (55). More importantly, activation of FOXO3 promoted stress resistance in differentiated human vascular endothelial and smooth muscle cells which related to cellular aging (56). This may provide additional evidence that miR-34a promotes vascular aging and senescence by targeting FOXO3. The above results show that inhibition of miR-34a alleviated cellular senescence and further improved cardiac and vascular function, which may provide a new approach for protecting against radiotherapyinduced cardiac injury and HF.

\section{MIR-34A AND CARDIOVASCULAR FIBROTIC REMODELING}

Myocardial inflammation and oxidative stress play critical roles in cardiac fibrosis and remodeling (57). It has been well-documented that miR-34a contributes to cardiac fibrosis and aging (58). The important pathological reactions that affect ventricular remodeling post MI encompass myocardial apoptosis, myocardial pathological hypertrophy, cellular senescence, and extracellular matrix metabolism disorder (59). It was identified that miR-34a could modulate TGF- $\beta 1$ induced myocardial proliferation and ECM deposition of rat cardiac fibroblasts by targeting c-ski. MiR-34a inhibitor alleviated rat cardiomyocyte proliferation and ECM deposition induced by TGF- $\beta 1$ (Table 1; Figure 2) (23). A recent study indicated that sevoflurane preconditioning inhibited cardiomyocyte apoptosis and reduced cardiac injury in hypoxia/reoxygenation $(H / R)$ stimulated H9C2 cells. MiR-34a-5p attenuated the protective effect of preconditioning with sevoflurane in H/R induced H9C2 cells via targeting syntaxin $1 \mathrm{~A}$ (60). MiR-34a inhibition has been shown to alleviate ventricular remodeling and improve cardiac function after myocardial infarction in animal models (20). Inhibition of miR-34a-5p promoted adipose-derived stem cell proliferation and migration to protect the myocardium against MI damage by activating the expression of clq/tumor necrosis factor related protein-9 (CTRP9) (61). Anti-miR34 attenuates MI-induced ventricular remodeling and atrial enlargement and improves cardiac function by targeting Notch 1 (Table 1) (6). Furthermore, miR-34a plays an important role in regulating vascular smooth muscle cell functions and neointima hyperplasia, indicating its potential treatment application for vascular diseases (62). The expression of miR-34a decreased in hypoxia-induced human pulmonary artery smooth muscle cells and the reduction in miR-34a increased proliferation, conversely, overexpression of miR-34a reversed the above effects by targeting platelet-derived growth factor receptor alpha (PDGFRA). PDGFRA is an important regulator in pulmonary artery hypertension mediates cell proliferation and vascular remolding (63). In this regard, in primary hypertension, miR-34a has not been reported to regulate vascular remolding via targeting PDGFRA. These miR-34a-mediated apoptosis, proliferation and necrosis ultimately contribute to cardiac remodeling (64). Contrary to most studies, a recent report shows that miR-34a ameliorates myocardial fibrosis by reducing type I collagen production, cell viability, and migration and improves cell function in diabetic cardiomyopathy (65). In general, miR$34 \mathrm{a}$ inhibition alleviated cardiac and vascular remodeling post ischaemic disease. Glucose metabolism-related cardiac fibrosis may result in differential targeting effects of miR-34a.

Taken together, these findings show that inhibition of miR-34a exerts a protective effect on the pathophysiology of cardiovascular diseases and is a potential therapeutic strategy for improving cardiac function.

\section{ROLES OF MIR-34A IN MI AND HF}

MI remains a leading cause of morbidity and mortality worldwide. The infarcted heart is characterized by a loss of cells from death and myocardial fibrotic scarring. Cardiac hypertrophy and fibrosis largely lead to thickening and stiffening of the ventricular wall, further contributing to cardiac remodeling that ultimately results in cardiac dysfunction and subsequent heart failure $(66,67)$. MiR-34a is involved in a variety of pathological process of AMI through regulating cardiomyocyte proliferation, migration, apoptosis and remodeling. The expression of miR-34a increased in an MI rat model, leading to myocardial apoptosis, fibrosis and cardiac dysfunction through the Wnt/ $\beta$-catenin pathway, indicating that miR-34a may be a potential therapeutic target for MI (68). In this regard, a recent study demonstrated that miR-34a was highly expressed in the heart tissue of AMI, which promoted cell apoptosis and oxidative stress. The results indicated that inhibition of miR-34a attenuated myocardial injury by multiple gene regulation of cellular phenotypes (69). Recent studies have shown that some mature miRs are also modified by $\mathrm{m} 6 \mathrm{~A} / \mathrm{m} 5 \mathrm{C}$ methylation, and that these modified mature miRs are significantly differentially expressed among cancer tissues (70). Similarly in the cardiovascular system, methylation of miR-34a promoted by Bcl-6 has a cardioprotective effect on AMI via the EZH2/miR-34a/CTRP9 axis (69). In the early stage of AMI, prevention of heart failure and left ventricular remodeling are closely related to the prognosis of patients, and left ventricular remodeling after AMI is associated with poor prognosis (68). It is becoming increasingly clear that miRs are promising predictors for cardiovascular pathological processes, 
including MI, myocardial remodeling and progression to heart failure. Long-term remodeling is associated with increased risk of cardiovascular death. Thus, early identification of ventricular remodeling is essential for clinical medicine (71). MiR-34a is upregulated and associated with left ventricular diastolic dimension in the convalescent stage of AMI patients who survive AMI but ultimately experience HF within 1 year (72). In addition, miR-34a exacerbated cardiac fibrosis and left ventricular dysfunction in the early stage of HF post AMI. It was demonstrated that miR-34a serves as an available predictor for future progression of HF post AMI (73). The results implied that miR-34a is an important biomarker for predicting left ventricular (LV) remodeling after AMI. Elevated miR-34a levels impair myocardial excitation contraction coupling which further leads to cardiac dysfunction through targeting Jph2. Importantly, it was demonstrated that intervention of this pathway with miR-34a antagonist significantly alleviated the heart failure in RBFox2 KO mice (24). These results indicated that inhibition of miR-34a plays a key role in controlling cell viability and cardiomyocyte apoptosis further improving cardiac function in $\mathrm{MI}$ and HF.

\section{ROLES OF MIR-34A IN I/R INJURY}

Cardiovascular disease accounts for more than $40 \%$ of pathological occurrences, and the mortality and prevalence have increased in recent years (74). Ischaemic heart disease is a main cause of cardiovascular diseases, which mostly leads to $\mathrm{MI}$ and cardiac dysfunction $(75,76)$. The roles of miRs in $\mathrm{I} / \mathrm{R}$ injury are mediated through the regulation of essential signaling pathways involved in necrosis, apoptosis, oxidative stress, inflammation, fibrosis and angiogenesis (77). It has been demonstrated that overexpression of miR-34a aggravates myocardial injury by increasing cell apoptosis and infarct size and decreasing LV function, while miR-34a suppression ameliorates myocardial I/R injury (35). Consistent with the above results, a recent study showed that miR-34a-5p inhibitor attenuated myocardial $\mathrm{I} / \mathrm{R}$ injury by alleviating apoptosis rate and reducing infarct size and ROS accumulation through targeting Notch receptor 1 signaling (76). Crocin, one of the active components of saffron, has been identified to suppress I/R-induced endoplasmic reticulum stress and cardiomyocyte apoptosis through downregulation of miR-34a and activation of the SIRT1/NRF2 pathway (Table 1; Figure 2) (25). Accordingly, miR-34a inhibition protected cardiomyocytes against I/R injury, and future studies should be investigated the efficacy of treatment with miR-34a inhibitor in $I / R$ patients and the underlying mechanisms.

\section{ROLES OF MIR-34A IN CARDIOMYOPATHY}

Cardiomyopathy is a disease that negatively affects cardiac function and can be classified into primary and secondary categories. Hypertrophic cardiomyopathy is the most common primary cardiomyopathy. More importantly, diabetes-induced cardiac dysfunction has been increasingly attracted worldwide; however, reports of mechanism of diabetic cardiomyopathy are limited (78-80). MiR-34a increased high glucose-induced inflammation, oxidative stress and cell death by targeting SIRT1 in H9C2 cells (81). MiR-34a was overexpressed to promote apoptosis in the diabetic heart and glucose control did not change the expression of miR-34a (82). In addition, transfection with miR-34a inhibitor significantly reduced cell apoptosis in diabetic cardiomyopathy. Treatment with dihydromyricetin decreased miR-34a expression further alleviating autophagy in high glucose-induced cardiomyocytes and in the heart tissue of diabetic mice to ameliorate cardiac dysfunction (44). Hypertension-induced hypertrophic cardiomyopathy increases the occurrence of cardiovascular events. MiR-34a has been shown to be a negative regulator in hypertrophic cardiomyopathy to aggravate myocardial cell inflammation and immune responses through TGF- $\beta /$ Smad signaling pathway (83). In particular, silencing miR-34a alone serves a protective role in moderate cardiomyopathy while anti-miR-34a does not alter the severe hypertrophic cardiomyopathy phenotype (84).

\section{ROLES OF MIR-34A IN ATHEROSCLEROSIS}

The development of atherosclerosis is facilitated by the presence of concomitant risk factors, encompassing dyslipidaemial, leading to a chronic inflammatory reaction in the vessel wall. Endothelial cells (ECs) and vascular smooth muscle cells (VSMCs) are also involved in the development of atherosclerotic vascular disease (85). Macrophages play an important role in the pathogenesis of atherosclerosis by regulating inflammatory response and foam cell formation. MiR-34a regulated cholesterol effusion and inflammation in macrophages, reversed cholesterol transport, and promoted atherosclerosis by coordinating regulation of several genes related to the pathogenesis of atherosclerosis. Importantly, the inhibition of miR-34a significantly prevented the progression of atherosclerosis and reversed atherosclerosis via multiple signaling and different cell types $(26,85)$. In light of high level of miR-34a in vascular aging, it induces senescence and the acquisition of a senescence associated secretory phenotype in VSMCs and ECs. MiR-34a has been reported to trigger ECs aging through repression of SIRT1, whereas antagonism of miR-34a reduced ECs apoptosis and the development of atherosclerosis in $\mathrm{ApoE}^{-/-}$mice $(26,86,87)$. Interestingly, a recent study indicated that miR-34a/SIRT1/FOXO3 may play a vital role in reversing ox-LDL-induced oxidative stress in HUVECs by genistein (Figure 2) (21). Indoxyl sulfate can promote the process of atherosclerosis through upregulating miR-34a expression and inhibiting the Notch signaling pathway (27). The miR$34 \mathrm{a} / \mathrm{HNF} 4 \alpha$ pathway may play a critical role in the pathogenesis of non-alcoholic fatty liver disease and regulate plasma lipid and lipoprotein metabolism. It was identified that miR-34a reduced the development of atherosclerosis in $\mathrm{ApoE}^{-/-}$mice by inhibiting HNF4 $\alpha$ expression (Table 1) (26). Furthermore, a recent study suggested that miR-34a may be a promising target for the treatment of atherosclerosis as prevents cell growth and 
promotes apoptosis in atherosclerosis by regulating $\mathrm{Bcl} 2$, while deletion of miR-34a ameliorates atherosclerotic lesions in highfat diet induced $\mathrm{ApoE}^{-/-}$mice (87). Interestingly, miRs in plasma are emerging as novel biomarkers for predicting multiple diseases. High level of miR-34a was related to coronary artery disease independently [OR [95\% CI: 3.87 (1.56-9.56)]; $P=0.003$ ] and the increased level was associated with expression of SIRT1, JAG1,CTNNB1, ATF1, and Notch2 inversely (88). Thus, miR34 a plays a central role by promoting inflammation, apoptosis and senescence in macrophages, ECs and VAMCs to exacerbated atherosclerosis progression.

\section{ROLES OF MIR-34A IN HYPERTENSION}

Primary hypertension is a common chronic disease that usually causes other health complications, such as coronary artery disease, stroke, renal failure and heart failure, and poses a great threat to human health $(89,90)$. Currently, the relationship between miR-34a and hypertension is relatively limited (91). Research has shown that miR-34a upregulated in the peripheral blood of patients with hypertension, and that upregulated miR-34a may promote vascular endothelial injury by targeting TIGF2 (89). The elevating miR-34a expression in hypertension increased the risk of vascular disease and related cardiovascular events. In hypertension-induced renal injury, urinary SIRT1 expression was decreased by miR-34a, indicating that SIRT1 is a potential method to evaluate renal injury in hypertensive patients (92). In contrary, a recent study showed that miR-34a reduces urinary microalbumin content in hypertensive mice and protects renal function targeting plasminogen activator inhibitor. The inhibition of miR-34a increased the levels of urinary microalbumin content and ACE protein, which contribute to renal damage in hypertensive mice (91). In general, miR-34a plays a critical role not only in hypertension but also in hypertension-related complications. The potential mechanisms between miR-34a and hypertension need further exploration.

\section{ROLES OF MIR-34A IN AF}

AF is the most common symptomatic cardiac arrhythmia in clinical medicine and shows an increasing prevalence with age. AF leads substantially to morbidity and mortality in the world (93). AF was divided into three groups at three durations (duration since diagnosis of AF). The 12-month and 24-month groups exhibited upregulated expression levels of miR-34a-5p (94). MiR-34a plays a critical role in promoting atrial electrical remodeling and the development of $\mathrm{AF}$ by inhibiting the expression of Ank-B (93). The present study revealed several novel persistent AF-associated miRs, including miR-34a-5p, which might target calcineurin1 and protein phosphatase three regulatory subunit $B$ alpha to regulate persistent AF through the calcineurin-nuclear factor of activated T cells signaling pathway (95). These results provide valuable insights into the underlying mechanism of AF. The above results indicated that miR-34a may be a promising clinical diagnostic tool in the early stage of AF.

\section{ANTI-MIR-34A THERAPY IN CVDS}

It is well-known that miR-34a is a tumor suppressive miR in various tumor diseases. MiR-34a has been identified to have therapeutic potential for cancer. A recent study indicated that co-delivery 5-fluorouracil and miR-34a mimic improved the apoptotic effect and inhibited the metastasis of colorectal cancer cells (96). Further study demonstrated that pre-miR34a transfection suppressed the expression of target genes, induced apoptosis and decreased the proliferation rate in gastric cancer (97). More importantly, this review showed that miR-34a plays a negative role in the progression of CVDs. Transfection with bone marrow-derived molecular cells promoted the release of IGF, which inhibited the expression of pre-miR-34a, thereby reducing cardiomyocyte apoptosis (98). Additionally, in calcific aortic valve stenosis model mice, locked nucleic acid-modified oligonucleotide (LNA)-miR-34a inhibitor attenuated the development of aortic valve stenosis and calcification (Table 1) (28). Inhibition of the miR-34 family attenuates pathological cardiac remodeling and atrial enlargement post AMI. Of interest, anti-miR-34a treatment ameliorated cardiac dysfunction by improving the cardiac molecular profile in females compared with males. More importantly, chronic administration of LNA-anti-miR-34 had no adverse effects on heart tissue morphology (99). The anti-miR-34 family, not anti-miR-34a only, shows a stronger therapeutic effect in cardiovascular disease, possibly due to regulating miRs and mRNA targets (100). Collectively, anti-miR-34a therapy is critical for CVDs and it is essential to explore the potential benefits of miR-34a inhibitor treatment in CVDs.

\section{CONCLUSION AND PROSPECTION}

MiR-34a plays a vital role in the process of cardiovascular diseases. Recently, clinical and experimental studies have demonstrated that miR-34a plays a crucial role in diverse cardiac biological pathways that induce cardiovascular injury and dysfunction. MiR-34a overexpression has been revealed to blunt autophagy and promote cardiovascular apoptosis, inflammation, fibrosis, remodeling, aging and heart dysfunction. More importantly, the inhibition of miR-34a has been shown to exert pro-autophagic, anti-apoptotic, anti-oxidant, and antifibrotic effects in the cardiovascular system. This review systematically outlined the regulatory roles of miR-34a in cardiovascular dysfunction and provided evidence to support miR-34a as a potential therapeutic target for the treatment of cardiovascular diseases. More preclinical and clinical trials are needed to identify the potential benefits and side effects of antimiR-34a therapy in cardiovascular diseases.

\section{AUTHOR CONTRIBUTIONS}

$\mathrm{C}-\mathrm{CH}$ and $\mathrm{X}-\mathrm{ML}$ drafted the manuscript. L-RL revised the manuscript. L-FW and J-CZ designed and provided guidance for the manuscript. All authors have read and approved the final manuscript. 


\section{FUNDING}

This work was supported by the General Program and the National Major Research Plan Training Program

\section{REFERENCES}

1. Kalayinia S, Arjmand F, Maleki M, Malakootian M, Singh CP. MicroRNAs: Roles in cardiovascular development and disease. Cardiovasc Pathol. (2021) 50:107296. doi: 10.1016/j.carpath.2020.107296

2. Song $\mathrm{R}, \mathrm{Hu} \mathrm{X}$, Zhang L. Mitochondrial MiRNA in cardiovascular function and disease. Cells-Basel. (2019) 8:1475. doi: 10.3390/cells8121475

3. Maroof H, Salajegheh A, Smith RA, Lam AK. Role of microRNA-34 family in cancer with particular reference to cancer angiogenesis. Exp Mol Pathol. (2014) 97:298-304. doi: 10.1016/j.yexmp.2014.08.002

4. Zhang L, Liao Y, Tang L. MicroRNA-34 family: A potential tumor suppressor and therapeutic candidate in cancer. J Exp Clin Canc Res. (2019) 38:1059. doi: 10.1186/s13046-019-1059-5

5. Li XJ, Ren ZJ, Tang JH. MicroRNA-34a: A potential therapeutic target in human cancer. Cell Death Dis. (2014) 5:e1327. doi: 10.1038/cddis.2014.270

6. Bernardo BC, Gao XM, Winbanks CE, Boey EJH, Tham YK, Kiriazis H, et al. Therapeutic inhibition of the miR-34 family attenuates pathological cardiac remodeling and improves heart function. Proc Natl Acad Sci USA. (2012) 109:17615-20. doi: 10.1073/pnas.1206432109

7. Zhang DG, Zheng JN, Pei DS. P53/microRNA-34-induced metabolic regulation: New opportunities in anticancer therapy. Mol Cancer. (2014) 13:115. doi: 10.1186/1476-4598-13-115

8. Misso G, Di Martino MT, De Rosa G, Farooqi AA, Lombardi A, Campani V, et al. Mir-34: A new weapon against cancer? Mol Ther Nucleic Acids. (2014) 3:e194. doi: 10.1038/mtna.2014.47

9. Rokavec M, Li H, Jiang L, Hermeking H. The p53/miR34 axis in development and disease. J Mol Cell Biol. (2014) 6:214-30. doi: 10.1093/jmcb/mju003

10. Li WJ, Wang Y, Liu R, Kasinski AL, Shen H, Slack FJ, et al. MicroRNA-34a: Potent tumor suppressor, cancer stem cell inhibitor, and potential anticancer therapeutic. Front Cell Dev Biol. (2021) 9:640587. doi: 10.3389/fcell.2021.640587

11. He M, Gao L, Zhang S, Tao L, Wang J, Yang J, et al. Prognostic significance of miR-34a and its target proteins of FOXP1, p53, and BCL2 in gastric MALT lymphoma and DLBCL. Gastric Cancer. (2014) 17:43141. doi: 10.1007/s10120-013-0313-3

12. Piegari E, Cozzolino A, Ciuffreda LP, Cappetta D, De Angelis A, Urbanek K, et al. Cardioprotective effects of miR-34a silencing in a rat model of doxorubicin toxicity. Sci Rep-Uk. (2020) 10:69038. doi: 10.1038/s41598-020-69038-3

13. Dong FF, Dong SH, Liang Y, Wang K, Qin YW, Zhao XX. MiR-34a promotes myocardial infarction in rats by inhibiting the activity of SIRT1. Eur Rev Med Pharmacol Sci. (2019) 23:7059-65. doi: 10.26355/eurrev_201908_18750

14. Baker JR, Vuppusetty C, Colley T, Papaioannou AI, Fenwick P, Donnelly $\mathrm{L}$, et al. Oxidative stress dependent microRNA-34a activation via PI3K $\alpha$ reduces the expression of sirtuin-1 and sirtuin-6 in epithelial cells. Sci Rep-Uk. (2016) 6:35871. doi: 10.1038/srep35871

15. Raddatz MA, Vander Roest MJ, Merryman WD. Notch1 suppression by microRNA-34a: A new mechanism of calcific aortic valve disease. Cardiovasc Res. (2020) 116:871-3. doi: 10.1093/cvr/cvz280

16. Wu K, Xiao Q, Yang Y, Xu J, Zhang F, Liu C, et al. MicroRNA-34a modulates the Notch signaling pathway in mice with congenital heart disease and its role in heart development. J Mol Cell Cardiol. (2018) 114:3008. doi: 10.1016/j.yjmcc.2017.11.015

17. Yu N, Wu JL, Xiao J, Fan L, Chen SH, Li W. HIF-1alpha regulates angiogenesis via Notch1/STAT3/ETBR pathway in trophoblastic cells. Cell Cycle. (2019) 18:3502-12. doi: 10.1080/15384101.2019.1689481

18. Sakai S, Maruyama H, Kimura T, Tajiri K, Honda J, Homma S, et al. Antagonists to endothelin receptor type B promote apoptosis in of the National Natural Science Foundation of China [92168117; 81770253; 91849111 and 81370362] and Talent project of Beijing Chaoyang Hospital Affiliated to Capital Medical University. human pulmonary arterial smooth muscle cells. Life Sci. (2016) 159:11620. doi: 10.1016/j.lfs.2016.03.044

19. Huang Y, Qi Y, Du JQ, Zhang DF. MicroRNA-34a regulates cardiac fibrosis after myocardial infarction by targeting Smad4. Expert Opin Ther Targets. (2014) 18:1355-65. doi: 10.1517/14728222.2014.961424

20. Boon RA, Iekushi K, Lechner S, Seeger T, Fischer A, Heydt S, et al. MicroRNA-34a regulates cardiac ageing and function. Nature. (2013) 495:107-10. doi: 10.1038/nature11919

21. Zhang $\mathrm{H}$, Zhao $\mathrm{Z}$, Pang $\mathrm{X}$, Yang J, Yu $\mathrm{H}$, Zhang $\mathrm{Y}$, et al. MiR$34 \mathrm{a} /$ sirtuin-1/foxo3a is involved in genistein protecting against ox-LDLinduced oxidative damage in HUVECs. Toxicol Lett. (2017) 277:11522. doi: 10.1016/j.toxlet.2017.07.216

22. Li J, Gong J, Li X, Shen L, Xie Y, Zhang R. MicroRNA-34a promotes CMECs apoptosis and upregulate inflammatory cytokines, thus worsening CMECs damage and inhibiting angiogenesis by negatively targeting the Notch signaling pathway. J Cell Biochem. (2019) 120:1598-609. doi: 10.1002/jcb.27433

23. Zhang C, Zhang Y, Zhu H, Hu J, Xie Z. MiR-34a/miR-93 target c-Ski to modulate the proliferaton of rat cardiac fibroblasts and extracellular matrix deposition in vivo and in vitro. Cell Signal. (2018) 46:14553. doi: 10.1016/j.cellsig.2018.03.005

24. Hu J, Gao C, Wei C, Xue Y, Shao C, Hao Y, et al. RBFox2-miR-34a-Jph2 axis contributes to cardiac decompensation during heart failure. Proc Natl Acad Sci USA. (2019) 116:6172-80. doi: 10.1073/pnas.1822176116

25. Wang X, Yuan B, Cheng B, Liu Y, Zhang B, Wang X, et al. Crocin alleviates myocardial Ischemia/Reperfusion-Induced endoplasmic reticulum stress via regulation of miR-34a/Sirt1/Nrf2 pathway. Shock. (2019) 51:12330. doi: 10.1097/SHK.0000000000001116

26. Xu Y, Xu Y, Zhu Y, Sun H, Juguilon C, Li F, et al. Macrophage miR-34a is a key regulator of cholesterol efflux and atherosclerosis. Mol Ther. (2020) 28:202-16. doi: 10.1016/j.ymthe.2019.09.008

27. Li X, Lu Z, Zhou F, Jin W, Yang Y, Chen S, et al. Indoxyl sulfate promotes the atherosclerosis through up-regulating the miR-34a expression in endothelial cells and vascular smooth muscle cells in vitro. Vasc Pharmacol. (2020) 131:106763. doi: 10.1016/j.vph.2020.106763

28. Toshima T, Watanabe T, Narumi T, Otaki Y, Shishido T, Aono T, et al. Therapeutic inhibition of microRNA-34a ameliorates aortic valve calcification via modulation of Notch1-Runx2 signalling. Cardiovasc Res. (2020) 116:983-94. doi: 10.1093/cvr/cvz210

29. Dorn GN. MiR-34a and the cardiomyopathy of senescence: SALT PNUTS, SALT PNUTS! Cell Metab. (2013) 17:62930. doi: 10.1016/j.cmet.2013.04.004

30. Natarajan SK, Stringham BA, Mohr AM, Wehrkamp CJ, Lu S, Phillippi MA, et al. FoxO3 increases miR-34a to cause palmitate-induced cholangiocyte lipoapoptosis. J Lipid Res. (2017) 58:866-75. doi: 10.1194/jlr.M071357

31. Zhang FM, Zheng WH, Wang HJ. MiR-34a-5p inhibition attenuates LPSinduced endothelial cell injury by targeting FOXM1. Eur Rev Med Pharmacol Sci. (2020) 24:10829-38. doi: 10.26355/eurrev_202010_23445

32. Del RD, Amgalan D, Linkermann A, Liu Q, Kitsis RN. Fundamental mechanisms of regulated cell death and implications for heart disease. Physiol Rev. (2019) 99:1765-817. doi: 10.1152/physrev.00022.2018

33. Ventura A, Kirsch DG, McLaughlin ME, Tuveson DA, Grimm J, Lintault L, et al. Restoration of p53 function leads to tumour regression in vivo. Nature. (2007) 445:661-5. doi: 10.1038/nature05541

34. Mak TW, Hauck L, Grothe D, Billia F. P53 regulates the cardiac transcriptome. Proc Natl Acad Sci USA. (2017) 114:23316. doi: 10.1073/pnas.1621436114

35. Fu BC, Lang JL, Zhang DY, Sun L, Chen W, Liu W, et al. Suppression of miR34a expression in the myocardium protects against Ischemia-Reperfusion 
injury through SIRT1 protective pathway. Stem Cells Dev. (2017) 26:127082. doi: $10.1089 / \mathrm{scd} .2017 .0062$

36. Liang Y, Liu H, Zhu J, Song N, Lu Z, Fang Y, et al. Inhibition of p53/miR34a/SIRT1 axis ameliorates podocyte injury in diabetic nephropathy. Biochem Bioph Res Co. (2021) 559:48-55. doi: 10.1016/j.bbrc.2021. 04.025

37. Yacoub R, Lee K, He JC. The role of SIRT1 in diabetic kidney disease. Front Endocrinol. (2014) 5:166. doi: 10.3389/fendo.2014.00166

38. Shi K, Sun H, Zhang H, Xie D, Yu B. MiR-34a-5p aggravates hypoxiainduced apoptosis by targeting ZEB1 in cardiomyocytes. Biol Chem. (2019) 400:227-36. doi: 10.1515/hsz-2018-0195

39. Fomison-Nurse I, Saw E, Gandhi S, Munasinghe PE, Van Hout I, Williams $\mathrm{M}$, et al. Diabetes induces the activation of pro-ageing miR-34a in the heart, but has differential effects on cardiomyocytes and cardiac progenitor cells. Cell Death Differ. (2018) 25:1336-49. doi: 10.1038/s41418-017-0047-6

40. Wang SP, Wang D, Li HX, Liu L, Duan XH. Influence of miR-34a on cerebral neuronal apoptosis in rats with cerebral ischemia reperfusion through the Notch1 signaling pathway. Eur Rev Med Pharmacol Sci. (2019) 23:804957. doi: 10.26355/eurrev_201909_19021

41. Wu X, Wang $\mathrm{L}$, Wang $\mathrm{K}$, Li J, Chen $\mathrm{R}$, Wu $\mathrm{X}$, et al. ADAR2 increases in exercised heart and protects against myocardial infarction and doxorubicin-induced cardiotoxicity. Mol Ther. (2021) 30:1-15. doi: 10.1016/j.ymthe.2021.07.004

42. Bharath LP, Rockhold JD, Conway R. Selective autophagy in HyperglycemiaInduced microvascular and macrovascular diseases. Cells-Basel. (2021) 10:2114. doi: 10.3390/cells10082114

43. Qiao P, Yao L, Zeng Z. Catalpol-mediated microRNA-34a suppresses autophagy and malignancy by regulating SIRT1 in colorectal cancer. Oncol Rep. (2020) 43:1053-66. doi: 10.3892/or.2020.7494

44. Ni T, Lin N, Lu W, Sun Z, Lin H, Chi J, et al. Dihydromyricetin prevents diabetic cardiomyopathy via miR-34a suppression by activating autophagy. Cardiovasc Drugs Ther. (2020) 34:291-301. doi: 10.1007/s10557-02006968-0

45. Shao H, Yang L, Wang L, Tang B, Wang J, Li Q. MicroRNA-34a protects myocardial cells against ischemia-reperfusion injury through inhibiting autophagy via regulating TNFalpha expression. Biochem Cell Biol. (2018) 96:349-54. doi: 10.1139/bcb-2016-0158

46. Lv X, Wang K, Tang W, Yu L, Cao H, Chi W, et al. MiR-34a-5p was involved in chronic intermittent hypoxia-induced autophagy of human coronary artery endothelial cells via Bcl-2/beclin 1 signal transduction pathway. J Cell Biochem. (2019) 120:18871-82. doi: 10.1002/jcb.29207

47. Raucci A, Vinci MC. MiR-34a: A promising target for inflammaging and Age-Related diseases. Int J Mol Sci. (2020) 21:8293. doi: $10.3390 /$ ijms 21218293

48. Hu Y, Xia W, Hou M. Macrophage migration inhibitory factor serves a pivotal role in the regulation of radiation-induced cardiac senescencethrough rebalancing the microRNA-34a/sirtuin 1 signaling pathway. Int J Mol Med. (2018) 42:2849-58. doi: 10.3892/ijmm.2018. 3838

49. Li T, Pang Q, Liu Y, Bai M, Peng Y, Zhang Z. Sulforaphane protects human umbilical vein endothelial cells from oxidative stress via the miR-34a/SIRT1 axis by upregulating nuclear factor erythroid-2-related factor 2. Exp Ther Med. (2021) 21:186. doi: 10.3892/etm.2021.9617

50. Panizzi P, Swirski FK, Figueiredo JL, Waterman P, Sosnovik $\mathrm{DE}$, Aikawa $\mathrm{E}$, et al. Impaired infarct healing in atherosclerotic mice with Ly-6C(hi) monocytosis. J Am Coll Cardiol. (2010) 55:1629-38. doi: 10.1016/j.jacc.2009.08.089

51. Ridker PM, Libby P, MacFadyen JG, Thuren T, Ballantyne C, Fonseca F, et al. Modulation of the interleukin- 6 signalling pathway and incidence rates of atherosclerotic events and all-cause mortality: Analyses from the Canakinumab Anti-Inflammatory Thrombosis Outcomes Study (CANTOS). Eur Heart J. (2018) 39:3499-507. doi: 10.1093/eurheartj/ehy310

52. Shi YY, Ma YH, Zhang R, Li RS. Downregulation of miR-34a ameliorates inflammatory response and apoptosis induced by renal ischemia-reperfusion by promoting Kruppel-like factor 4 expression. Eur Rev Med Pharmacol Sci. (2020) 24:11683-9. doi: 10.26355/eurrev_202011_23813

53. Xia W, Zou C, Chen H, Xie C, Hou M. Immune checkpoint inhibitor induces cardiac injury through polarizing macrophages via modulating
microRNA-34a/Kruppel-like factor 4 signaling. Cell Death Dis. (2020) 11:2778. doi: 10.1038/s41419-020-02778-2

54. Li H, Hastings MH, Rhee J, Trager LE, Roh JD, Rosenzweig A. Targeting Age-Related pathways in heart failure. Circ Res. (2020) 126:53351. doi: 10.1161/CIRCRESAHA.119.315889

55. Raucci A, Macri F, Castiglione S, Badi I, Vinci MC, Zuccolo E. MicroRNA34a: The bad guy in age-related vascular diseases. Cell Mol Life Sci. (2021) 78:7355-78. doi: 10.1007/s00018-021-03979-4

56. Yan P, Li Q, Wang L, Lu P, Suzuki K, Liu Z, et al. FOXO3-Engineered human ESC-Derived vascular cells promote vascular protection and regeneration. Cell Stem Cell. (2019) 24:447-61.e8. doi: 10.1016/j.stem.2018.12.002

57. Bacmeister L, Schwarzl M, Warnke S, Stoffers B, Blankenberg S, Westermann $\mathrm{D}$, et al. Inflammation and fibrosis in murine models of heart failure. Basic Res Cardiol. (2019) 114:19. doi: 10.1007/s00395-019-0722-5

58. Verjans R, van Bilsen M, Schroen B. MiRNA deregulation in cardiac aging and associated disorders. Int Rev Cell Mol Biol. (2017) 334:20763. doi: 10.1016/bs.ircmb.2017.03.004

59. Bian W, Tian F, Jiang L, Sun Y, Wu S, Gao B, et al. Influence of miR34a on myocardial apoptosis in rats with acute myocardial infarction through the ERK1/2 pathway. Eur Rev Med Pharmaco. (2019) 23:303441. doi: 10.26355/eurrev_201904_17585

60. Wenlan L, Zhongyuan X, Shaoqing L, Liying Z, Bo Z, Min L. MiR-34a-5p mediates sevoflurane preconditioning induced inhibition of hypoxia/reoxygenation injury through STX1A in cardiomyocytes. Biomed Pharmacother. (2018) 102:153-9. doi: 10.1016/j.biopha.2018.03.002

61. Weng CF, Wu CF, Kao SH, Chen JC, Lin HH. Down-Regulation of miR$34 a-5 p$ potentiates protective effect of Adipose-Derived mesenchymal stem cells against ischemic myocardial infarction by stimulating the expression of C1q/Tumor necrosis Factor-Related protein-9. Front Physiol. (2019) 10:1445. doi: 10.3389/fphys.2019.01445

62. Chen Q, Yang F, Guo M, Wen G, Zhang C, Luong LA, et al. MiRNA34a reduces neointima formation through inhibiting smooth muscle cell proliferation and migration. J Mol Cell Cardiol. (2015) 89:7586. doi: $10.1016 /$ j.yjmcc.2015.10.017

63. Wang P, Xu J, Hou Z, Wang F, Song Y, Wang J, et al. MiRNA-34a promotes proliferation of human pulmonary artery smooth muscle cells by targeting PDGFRA. Cell Proliferat. (2016) 49:484-93. doi: 10.1111/cpr.12265

64. Wang Q, Yu X, Dou L, Huang X, Zhu K, Guo J, et al. MiR-154-5p functions as an important regulator of angiotensin II-Mediated heart remodeling. Oxid Med Cell Longev. (2019) 2019:8768164. doi: 10.1155/2019/8768164

65. Zhang XL, Zhang G, Bai ZH. MiR-34a attenuates myocardial fibrosis in diabetic cardiomyopathy mice via targeting Pin-1. Cell Biol Int. (2021) 45:642-53. doi: 10.1002/cbin.11512

66. Reed GW, Rossi JE, Cannon CP. Acute myocardial infarction. Lancet. (2017) 389:197-210. doi: 10.1016/S0140-6736(16)30677-8

67. Xiao Y, Zhao J, Tuazon JP, Borlongan CV, Yu G. MicroRNA133a and myocardial infarction. Cell Transplant. (2019) 28:831-8. doi: 10.1177/0963689719843806

68. Li JH, Dai J, Han B, Wu GH, Wang CH. MiR-34a regulates cell apoptosis after myocardial infarction in rats through the Wnt/betacatenin signaling pathway. Eur Rev Med Pharmacol Sci. (2019) 23:255562. doi: 10.26355/eurrev_201903_17404

69. Lin JM, Hsu CH, Chen JC, Kao SH, Lin YC. BCL-6 promotes the methylation of miR-34a by recruiting EZH2 and upregulating CTRP9 to protect ischemic myocardial injury. Biofactors. (2021) 47:386-402. doi: 10.1002/biof.1704

70. Konno M, Koseki J, Asai A, Yamagata A, Shimamura T, Motooka D, et al. Distinct methylation levels of mature microRNAs in gastrointestinal cancers. Nat Commun. (2019) 10:3888. doi: 10.1038/s41467-019-11826-1

71. Lv P, Zhou M, He J, Meng W, Ma X, Dong S, et al. Circulating miR-208b and miR-34a are associated with left ventricular remodeling after acute myocardial infarction. Int J Mol Sci. (2014) 15:577488. doi: 10.3390/ijms15045774

72. Matsumoto S, Sakata Y, Suna S, Nakatani D, Usami M, Hara M, et al. Circulating p53-Responsive MicroRNAs are predictive indicators of heart failure after acute myocardial infarction. Circ Res. (2013) 113:3226. doi: 10.1161/CIRCRESAHA.113.301209

73. Zhou R, Wang L, Zhao G, Chen D, Song X, Momtazi Borojeni AA, et al. Circulating exosomalmicroRNAs as emerging non-invasive clinical 
biomarkers in heart failure: Mega bio-roles of a nano bio-particle. Iubmb Life. (2020) 72:2546-62. doi: 10.1002/iub.2396

74. Xia YW, Wang SB. Microvesicles containing microRNA-21 induce myocardial fibrosis via AKT pathway. Eur Rev Med Pharmacol Sci. (2018) 22:4634-41. doi: 10.26355/eurrev_201807_15522

75. Vilahur G, Juan-Babot O, Pena E, Onate B, Casani L, Badimon L. Molecular and cellular mechanisms involved in cardiac remodeling after acute myocardial infarction. J Mol Cell Cardiol. (2011) 50:52233. doi: 10.1016/j.yjmcc.2010.12.021

76. Wang Z, Wang Z, Wang T, Yuan J, Wang X, Zhang Z. Inhibition of miR-34a-5p protected myocardial ischemia reperfusion injury-induced apoptosis and reactive oxygen species accumulation through regulation of Notch Receptor 1 signaling. Rev Cardiovasc Med. (2019) 20:18797. doi: 10.31083 /j.rcm.2019.03.545

77. Ghafouri-Fard S, Shoorei H, Taheri M. Non-coding RNAs participate in the ischemia-reperfusion injury. Biomed Pharmacother. (2020) 129:110419. doi: 10.1016/j.biopha.2020.110419

78. Braunwald E. Cardiomyopathies: An overview. Circ Res. (2017) 121:71121. doi: 10.1161/CIRCRESAHA.117.311812

79. Dadson K, Hauck L, Billia F. Molecular mechanisms in cardiomyopathy. Clin Sci (Lond). (2017) 131:1375-92. doi: 10.1042/CS20160170

80. Tan Y, Zhang Z, Zheng C, Wintergerst KA, Keller BB, Cai L. Mechanisms of diabetic cardiomyopathy and potential therapeutic strategies: Preclinical and clinical evidence. Nat Rev Cardiol. (2020) 17:585-607. doi: 10.1038/s41569-020-0339-2

81. Gao L, Wang X, Guo S, Xiao L, Liang C, Wang Z, et al. LncRNA HOTAIR functions as a competing endogenous RNA to upregulate SIRT1 by sponging miR-34a in diabetic cardiomyopathy. J Cell Physiol. (2019) 234:4944-58. doi: 10.1002/jcp. 27296

82. Costantino S, Paneni F, Luscher TF, Cosentino F. MicroRNA profiling unveils hyperglycaemic memory in the diabetic heart. Eur Heart J. (2016) 37:572-6. doi: 10.1093/eurheartj/ehv599

83. Sun Y, Ren J, Wu WZ. Effect of MiR-34a on hypertensioninduced hypertrophic cardiomyopathy in rats via the TGFbeta1/Smads signaling pathway. Minerva Med. (2021) 112:4056. doi: $10.23736 / \mathrm{S} 0026-4806.19 .06192-5$

84. Bernardo BC, Gao XM, Tham YK, Kiriazis H, Winbanks CE, Ooi JY, et al. Silencing of miR-34a attenuates cardiac dysfunction in a setting of moderate, but not severe, hypertrophic cardiomyopathy. PLoS ONE. (2014) 9:e90337. doi: 10.1371/journal.pone.0090337

85. Feinberg MW, Moore KJ. MicroRNA regulation of atherosclerosis. Circ Res. (2016) 118:703-20. doi: 10.1161/CIRCRESAHA.115.306300

86. Ito $\mathrm{T}$, Yagi $\mathrm{S}$, Yamakuchi M. MicroRNA-34a regulation of endothelial senescence. Biochem Biophys Res Commun. (2010) 398:735-40. doi: 10.1016/j.bbrc.2010.07.012

87. Su G, Sun G, Liu H, Shu L, Liang Z. Downregulation of miR34a promotes endothelial cell growth and suppresses apoptosis in atherosclerosis by regulating Bcl-2. Heart Vessels. (2018) 33:118594. doi: 10.1007/s00380-018-1169-6

88. Gatsiou A, Georgiopoulos G, Vlachogiannis NI, Pfisterer L, Fischer A, Sachse $M$, et al. Additive contribution of microRNA-34a/b/c to human arterial ageing and atherosclerosis. Atherosclerosis. (2021) 327:4958. doi: 10.1016/j.atherosclerosis.2021.05.005

89. Liu S, Yi F, Cheng W, Qu X, Wang C. Molecular mechanisms in vascular injury induced by hypertension: Expression and role of microRNA-34a. Exp Ther Med. (2017) 14:5497-502. doi: 10.3892/etm.2017.5216

90. Liu Y, Dong Y, Dong Z, Song J, Zhang Z, Liang L, et al. Expression profiles of circular RNA in aortic vascular tissues of spontaneously hypertensive rats. Front Cardiovasc Med. (2021) 8:814402. doi: 10.3389/fcvm.2021.814402
91. Liu R, Yang L, Wei Q. MiR-34a targets PAI-1 to regulate urinary microalbumin and renal function in hypertensive mice. Eur J Med Res. (2020) 25:7. doi: 10.1186/s40001-020-00404-7

92. Martinez-Arroyo O, Ortega A, Galera M, Solaz E, Martinez-Hervas $S$, Redon J, et al. Decreased urinary levels of SIRT1 as non-invasive biomarker of early renal damage in hypertension. Int J Mol Sci. (2020) 21:6390. doi: 10.3390/ijms21176390

93. Zhu Y, Feng Z, Cheng W, Xiao Y. MicroRNA34a mediates atrial fibrillation through regulation of AnkyrinB expression. Mol Med Rep. (2018) 17:845765. doi: $10.3892 / \mathrm{mmr} .2018 .8873$

94. Wang H, Chen Y, Tao T, Zhao X, Wang Y, Luo J, et al. Identification of microRNA biomarkers in serum of patients at different stages of atrial fibrillation. Heart Lung. (2020) 49:902-8. doi: 10.1016/j.hrtlng.2020. 03.021

95. Xiao S, Zhou Y, Liu A, Wu Q, Hu Y, Liu J, et al. Uncovering potential novel biomarkers and immune infiltration characteristics in persistent atrial fibrillation using integrated bioinformatics analysis. Math Biosci Eng. (2021) 18:4696-712. doi: 10.3934/mbe.2021238

96. Xu J, Zhang G, Luo X, Wang D, Zhou W, Zhang Y, et al. Codelivery of 5-fluorouracil and miRNA-34a mimics by host-guest selfassembly nanocarriers for efficacious targeted therapy in colorectal cancer patient-derived tumor xenografts. Theranostics. (2021) 11:247589. doi: $10.7150 /$ thno. 52076

97. Jafari N, Abediankenari S, Hossein-Nataj H. MiR-34a mimic or pre-mir34a, which is the better option for cancer therapy? KatoIII as a model to study miRNA action in human gastric cancer cells. Cancer Cell Int. (2021) 21:178. doi: 10.1186/s12935-021-01872-5

98. Iekushi K, Seeger F, Assmus B, Zeiher AM, Dimmeler S. Regulation of cardiac microRNAs by bone marrow mononuclear cell therapy in myocardial infarction. Circulation. (2012) 125:1765-73. doi: 10.1161/CIRCULATIONAHA.111.079699

99. Bernardo BC, Ooi JY, Matsumoto A, Tham YK, Singla S, Kiriazis H, et al. Sex differences in response to miRNA-34a therapy in mouse models of cardiac disease: Identification of sex-, disease- and treatment-regulated miRNAs. $J$ Physiol. (2016) 594:5959-74. doi: 10.1113/JP272512

100. Ooi JYY, Bernardo BC, Singla S, Patterson NL, Lin RCY, McMullen JR. Identification of miR-34 regulatory networks in settings of disease and antimiR-therapy: Implications for treating cardiac pathology and other diseases. RNA Biol. (2017) 14:500-13. doi: 10.1080/15476286.2016. 1181251

Conflict of Interest: The authors declare that the research was conducted in the absence of any commercial or financial relationships that could be construed as a potential conflict of interest.

Publisher's Note: All claims expressed in this article are solely those of the authors and do not necessarily represent those of their affiliated organizations, or those of the publisher, the editors and the reviewers. Any product that may be evaluated in this article, or claim that may be made by its manufacturer, is not guaranteed or endorsed by the publisher.

Copyright (c) 2022 Hua, Liu, Liang, Wang and Zhong. This is an open-access article distributed under the terms of the Creative Commons Attribution License (CC BY). The use, distribution or reproduction in other forums is permitted, provided the original author(s) and the copyright owner(s) are credited and that the original publication in this journal is cited, in accordance with accepted academic practice. No use, distribution or reproduction is permitted which does not comply with these terms. 